\title{
Libertad y liberación. Puntos de contacto y de fricción en el primer y tercer mundo*
}

\section{Leonardo Boff.}

\section{Instituto Teológico Franciscano. Petrópolis, Brasil.}

El tema es muy complejo. Exige de cualquier expositor la capacidad de analizar un ingente cúmulo de datos y, al mismo tiempo, la capacidad de sintetizarlos. De esta síntesis deben surgir las principales directrices históricas que sean significativas para el tema propuesto.

Quisiera dejar en claro desde el principio que la interpretación que voy a ofrecer está condicionada por mi propio lugar social latinoamericano y por mi propia práctica personal histórica, común a tantos intelectuales de mi generación que se han solidarizado con la causa de los pobres, que reconocen -contra todas las difamaciones- el derecho y la dignidad de las luchas de los marginados, la relevancia ética de sus ideales, y que apoyan la esperanza histórica-política, de la que son portadores, en favor de una sociedad distinta, de corte democrático y social, con su correspondiente expresión religiosa y eclesial.

Desde esta opción previa voy a procurar -como en una lectura de ciegoponer de relieve los momentos más sobresalientes de la práctica y del pensamiento liberador de América Latina, y —desde América Latina- de aquellas tradiciones europeas que se inscriben en el marco de la liberación o que han influido en el despertar a la liberación. Somos muy conscientes de que leer es sicmpre releer, de que entender es siempre interpretar. Por ello -inexorablemente- cualquier punto de vista supone ver desde un punto. Ese punto es limitado, pero legítimo; $y$, en cuanto permite ver, es también objetivo. Mi punto de vista intenta ser el de los oprimidos, porque son ellos los que saben cuánto hace sufrir la opresión y cuán benéfica es la liberación.

* Conferencia dictada en la Universidad de Münster, Alemania, el 2B de septiembre de 1987, en el encuentro sobre "Alemania y América Latina en diálogo." 
Somos conscientes también de que no existe sólo una América Latina ni sólo una Europa. Como en un tel arqueológico, existen muchas capas en América Latina y en Europa, coexisten sincrónicamente muchos modos de producción, con contradicciones, superposiciones y yuxtaposiciones que no son siempre fáciles de ser analizadas desde una determinada totalidad dominante. ${ }^{1}$ A causa de esta dificultad objetiva, nuestra contribución posee claramente un carácter hipotético.

También queremos evitar una lectura idealista de las tradiciones europeas de la libertad y del pensamiento liberador latino-americano, como si, por sí mismas, las ideas moviesen el mundo. Por eso, en el análisis de cada proceso de cambio, mencionaremos su sujeto histórico correspondiente. El es el que se constituye en sujeto de las transformaciones y el que, de forma vital, da cucrpo a las ideas y hace la síntesis entre teoria y práctica. ${ }^{2}$

\section{Práctica y teoría liberadora en América Latina}

Vamos a comenzar por los procesos de liberación latinoamericanos. Por razones pedagógicas de exposición, distinguiremos cuatro fases, pues queremos subrayar cuatro sujetos históricos distintos.

\subsection{La Amerindia pre-colombina}

La Amerindia no fue descubierta por los españoles en 1492. Ya existía desde hacía cerca de 30.000 años. Sus habitantes vinieron, por el norte, a través del estrecho de Behring; por el sur, a través de la Antártica; y por el Pacílico, a través de las islas. Se fueron configurando diversas formaciones económico-sociales, desde microetnias y tribus familiares, hasta verdaderos imperios, centros de poder con sus metrópolis y con poblaciones de millones de habitantes, estratificadas en clases y solisticados cuerpos profesionales. ${ }^{3}$ Con los azlecas, los mayas y los incas, entre otros, estas culturas alcanzaron un avanzado estadio de desarrollo social. Consiguieron el cultivo de plantas que llegaron a formar parte de la dieta alimenticia de todo el mundo: el maíz, la mandioca, la papa pequeria, la papa dulce, el maní, la pimienta y una amplia variedad de frijoles; consiguieron también el procesamiento del tabaco y el almidón.

No debemos idealizar las culturas pre-colombinas, pues a pesar de sus avances en las comunicaciones, en los procesos de urbanización, en las matemáticas y la astronomia -utilizando el cero por lo menos mil años antes que los indostanes, quienes se lo transmiticron a los ärabes- tenían muchas contradicciones internas; en los imperios azteca e inca existía una férrea dominación de clase, la esclavitud y los sacrificios humanos. Sin embargo, eran culturas autárquicas y llegaron a crear civilizaciones originales.

La invasión ibérica de América, el genocidio al que fueron sometidos los indios, la contaminación de las enfermedades de los blancos, como la viruela, el sarampión, la gripe y la sífilis, produjeron la mayor hecatombe biológica de la que se tiene noticia en la historia. Mientras Lutero hacía su reforma y el concilio de 
Trento organizaba su contra-reforma (1545-1563), los españoles diezmaron bárbaramente las grandes culturas meso-americanas. En 50 años la población quedo reducida a una novena parte. En 1532 había en México aproximadamente $17 \mathrm{mi}$ llones de indígenas. Cincuenta años más tarde, en 1580, sólo quedaban dos millones de habilantes. ${ }^{4} \mathrm{Y}$ en las aulas del concilio de Trento no se escuchó ninguna voz de protesta.

Ese proceso continúa todavía hasta el día de hoy. En Brasil, los indios kayapó vivían en 1903 en las márgenes del río Araguaia. Según los datos de los padres dominicos que trabajaban con ellos eran entonces de seis a ocho mil. En 1918 eran unos 500. En 1929, sólo 27. En 1958 sólo había una única mujer sobreviviente. ${ }^{5}$ Ahora es una tribu totalmente extinguida. El profeta y obispo Bartolomé de las Casas, poseído de una sagrada ira, proclama después de descubir la destrucción de las Indias: "Las gentes naturales...tienen el derecho adquirido de hacernos una guena justísima y de eliminamos de la faz de la tierra, y este derecho les asistirá hasta el día del juicio final."6

Comprendemos, por ello - y nos adherimos a ello-, que los historiadores indígenas no acepten la expresión "descubrimiento" y "conquista" de América Latina. Prefieren usar la expresión "invasión colonizadora"7 que sometió los cuerpos violentamente y avasalló las almas. ${ }^{8}$ Cuando hablamos de conquista, se acepta un hecho consumado; cuando hablamos de invasión se hace una denuncia y se expresa una lucha continua de liberación. Desde ahí dcbcmos entender que, en julio de 1986, representantes de 15 naciones indígenas, en carta enviada a la ONU, rechazaran la celebración del quinto centenario del "descubrimiento" y de la primera "evangelización" de Amerindia. ¿Cómo se puede celcbrar lo que en verdad significó usurpación, desintegración cultural, dominación ideológica y muerte?

Lo que se hace necesario es más bien un jubilco penitencial y de radical revisión de las estrategias culturales y cvangelizadoras en una línea de liberación y de defensa y promoción de la vida indígena. El impacto y los engaños han traumatizado a las culturas amerindias hasta el día de hoy. Despreciadas, domesticadas, sojuzgadas, representan hoy el bloque histórico de los oprimidos que están despertando de la iniquidad a que se les sometió y a la urgencia de la liberación, es decir, la recuperación de la liberad cautiva.

\subsection{La invasión generadora de dependenciay opresión}

En 1492, Cristóbal Colón invadió América Latina anribando al Caribe. Puso nombre a la tierra que vio a lo lejos en un gesto bíblico de quien se considera dueño de ella: la llamó San Salvador. En su diario de abordo muestra inmediatamente su preocupación por el oro: 77 veces habla de oro en el relato. Lleva consigo algunos indígenas para mostrarlos en España. Esta invasión va a trasladar el centro geopolítico đel Mediterráneo al Allántico Norte, lo cual perdura hasta el día de hoy. De la América Latina sometida comienza a llegar a Europa, solamente en el siglo XVI, diez veces más plata y cinco veces más oro que antes. ${ }^{10}$ Se gesta aquí la acumulación del capital, nccesaria para mantener el capitalismo industrial 


\section{de Inglaterra y Holanda.}

Estos invasores irrumpieron en Amerindia para colonizar, es decir, para someter a todos sus pueblos a la primera civilización agrariomercantil a nivel mundial de la que da testimonio la historia. Como dice André Gunder Frank, las "encomiendas" y las "capitanías," creadas por la invasión, "pusieron a toda América en una situación de creciente subordinación y de dependencia colonial y neocolonial en relación al sistema mundial único del capitalismo comercial en expansión." 11 Lo específico de América Latina consiste en que, desde el principio, fue incorporada al sistema capitalista mercantil, en forma dependiente y asociada a las metrópolis coloniales. La economía rue concebida para la exportación, estaba basada en el sistema esclavista del trabajo, al principio indígena y, tras el debilitamiento total de éstos, de los negros traídos de Africa. ${ }^{12} \mathrm{EI}$ esclavo negro no sólo sustituyó al indígena, sino que fue convertido también en mercancía, pues era comprado; y sobre esa mercancía recaían impueslos y lasas que eran acumuladas por las metrópolis coloniales. Dice el antropólogo Darcy Riberio con acierto: "Las poblaciones esclavas se desgastan en el proceso productivo del mismo modo como, más tarde, se gastará el carbón o el petróleo, porque constituían el combustible de una economía basada principalmente en la energía muscular humana." 13 En la formación social latinoamericana se da, pues, una conjunción contradictoria de las relaciones de producción. Predomina el capitalismo mercantil colonial, pero dentro de él y sometidos a él aparecen otros modos de producción, trabajos forzados, elementos feudales y tribales, como reminiscencias de formas de producción de varias razas indígenas. Sin embargo, en todo ello está presente el carácter de explotación que, a su vez, encierra en sí mismo a lo que lo contradice: el anhelo dc liberación.

El profeta y defensor de los indígenas, Barolomé de las Casas, 14 intuyó perfectamente las dos estrategias de dominación de los invasores con respecto a las poblaciones autóctonas: "una, dominar a través de guerras injuslas, crueles, sangrientas y tiránicas;" otra, después de haber matado a todos los que se resislian y suspiraban por la libertad, oprimir "con la más dura, horrible y áspera servidumbre, en la que puedan ser puestos jamás hombres o bestias." 15 Es decir, primero llevando la guerra; después la dominación. ¿Y por qué tanta violencia? Bartolomé de las Casas da una respuesta y, con ello, desenmascara cuál es el proyecto de fondo que moviliza toda la invasión colonizadora: sólo para que los cristianos realicen "su fin último, que es el oro, y para hincharse de riqueza en pocos días, y, además, para alzarse a puestos muy elevados." 16

El sujeto histórico de la colonización son los españoles y portugueses como sus agentes. Los misioneros desempeñan una función ambigua: a través de la misión españolizan y portuguesizan a los indígenas y así los preparan para el sistema de dominación; ${ }^{17}$ por otro lado, se oponen a formas crueles de sometimiento y muchos se convierten en defensores de los indios: ${ }^{18}$ es su función de resistencia y de liberación. 


\subsection{El neocolonialismo: la independencia política y la nueva do- minación económica}

La independencia política de América Latina tuvo lugar entre 1808 y 1824. No fue el resultado de un proceso revolucionario popular, sino que fue llevada a cabo por la burguesía agraria, minera, mercantil, blanca y criolla, la cual desde hacía tiempo quería emanciparse de la dominación colonial española. ${ }^{19}$ Son, por tanto, grupos de clases dominantes, entre los cuales se distinguen principalmente dos tendencias. La tendencia conservadora, constituida por quienes quieren sustituir la gestión de los adminisradores españoles, asumir el poder político y reorientar la economía en favor de sus intereses de clase, elitista y antipopular. Se trata de la burguesía nacional, orientada hacia dentro, que quiere verse libre de las dependencias extranjeras. La tendencia liberal se orienta hacia afuera, asimila los ideales de democracia y libertad de Europa y Estados Unidos. Estos sectores quieren liberarse de la dependencia española para colocarse bajo otra dependencia, la de Inglaterra, que en ese momento poseía la hegemonía del capitalismo industrial y buscaba nuevos mercados. Triunfaron los liberales. Asumieron el poder, desmontaron las estructuras coloniales y se lamentaron de haber llegado tarde a la mesa de la civilización. Acusaron a la cultura colonial de feudalista y a la indígena de bárbara. Convirtieron a los diversos países de América Latina en exportadores de materias primas e importadores de manufacturas. En todo este proceso el pueblo estuvo ausente. Para el pueblo no cambió la naturaleza de la dominación, pues continuó siendo explocado y los negros continúan siendo esclavizados. Lo que cambió fue sólo la forma de la dominación: antes era española, ahora es nacional. No cambio el régimen de dependencia, sino que sólo se modificaron sus referentes: antes era España; ahora, Inglaterra.

La corriente liberal usó los términos democracia y libertad, como en Europa; pero con intereses distintos. En nombre de la libertad y de la democracia la burguesía europea combatía a los grandes propietarios de la tierra. En América Latina, en nombre de la democracia y de la libertad, los grandes terratenientes combatieron el monopolio colonial español. En Europa sirvió para crear los estados nacionales autónomos; en América Latina sirvió para crear sólo una independencia política, pero ligada a una nueva dependencia económica, de Inglaterra primero, desde 1929 de los Estados Unidos, y, finalmente, uras la postguerra, simplemente del capitalismo trasnacional.

En América Latina, desde que fue invadida hasta el día de hoy, se da una constante, con las sólo dos excepciones de Cuba y Nicaragua: siempre hemos vivido en régimen de dependencia-opresión; y la clase dominante, agraria, mercantil e industrial, siempre ha mantenido la hegemonia, en articulación con los centros capitalistas metropolitanos, generando subdesarrollo como consecuencia del tipo de desarrollo llevado a cabo por los países desarrollados. ${ }^{20}$ Estos controlan a los parses que les suministran materias primas, manteniéndolos dependientes en términos de tecnología, economía, finanzas, política y cultura. El capilalismo latinoamericano, dependiente y asociado, no ha resuelto ningún problema básico del pue- 
blo, como lo es el trabajo, la alimentación, la salud, la vivienda, la escuela, el esparcimiento. La democracia y la libertad han pertenecido a las clases dominantes y a sectores de otras clases, asociadas a aquéllas, pero nunca han sido vividas por el pueblo. Los diversos populismos launoamericanos, ${ }^{21}$ desde los años 30 , han servido solamente para evilar revoluciones populares, mediante la concesión de beneficios sociales que han mantenido al pueblo a remolque del proyecto de dominación de la burguesía nacional articulada con los intereses del capital transnacional.

\subsection{La irrupción de los pobres que buscan la liberación}

Dependencia externa y dominación interna es lo que caracteriza a las formaciones económico-sociales latinoamericanas. A partir de los años 30 en casi todo el continente surgió el despertar de aquellos que hasta entonces habían sido los invisibles de la historia: trabajadores, campesinos, indigenas y negros. Cayeron en la cuenta de que el desarrollo se lograba a costa de la miseria de las grandes mayorías. Descubrieron también que existía un nexo causal entre la expansión del capitalismo en los centros industriales y el fortalecimiento de las relaciones de dependencia - dominación en los países mantenidos en el subdesarrollo. 22 Para arrancar las raíces de la miseria y de la injusticia social no eran suficientes la modernización y el desartollo; se hacía necesaria una revolución social y un proceso de liberacion. Esa opción se vio reforzada por la victoria del socialismo en Rusia, en 1917; por el triunfo de la revolución socialista en Cuba, en 1959; y últimamente, en 1979, en Nicaragua.

La gran palabra, cargada de contcnido político, emocional, denunciador, utópico y religioso, es liberación. ${ }^{23}$ ¿Y quiénes la usan? Liberación es la palabra de aquellos que han tomado conciencia de su opresión histórica, que la rechazan y que quieren rescatar su libertad cautiva mediante un proyecto altemativo de sociedad de corte democrático, popular y social. Liberación es la acción que crea liberlad o que recupera la liberlad perdida. Quienes se comprometen con la liberación se oponen al sistema capitalista transnacional, se enfrentan a la dominación de la democracia burguesa nacional, asociada a la burguesía multinacional, y se alían con todos aquellos que también quieren una transformación. ${ }^{24} \mathrm{El}$ sujeto histórico de la liberación son los oprimidos, los condenados de la tierra, los hasta ahora ausentes de la escena histórica.

En este preciso contexto, ya en los inicios de siglo, en América Latina se entró en contacto con el socialismo de la Segunda Internacional y con el marxismo. ${ }^{25}$ Los militantes latinoamericanos asumieron el manxismo no debido a su carácter materialista y ateo, sino más bien como instrumento té́rico que ayuda a desenmascarar los mecanismos de opresión y, por ello, como arma de lucha política e ideológica contra el capitalismo opresor. ${ }^{26}$ José Carlos Mariálegui, pensador político peruano, ha sido quien ha elaborado más coherentemente la realidad latinoamericana desde una perspectiva marxista y revolucionaria. 
Para mejor comprender lo que significa liberación distingamos sus diversas dimensiones.

Contenido histórico-sociológico de la liberación. La categoría de liberación ya fue usada al final de los antos 60 entre sociólogos y politólogos en América Latina que intentaban entender el subdesarrollo a partir del propio subdesarrollo. La expresión implicaba una altemativa al desarrollismo, ofrecer un camino hacia una sociedad de corte democrático sin dependencias que significasen opresión.

Contenido político de la liberación. La palabra liberación traduce el proyecto de los oprimidos y de sus aliados y sirví́ para criticar a la democracia burgucsa, elitista y antipopular, que muchas veces generó, para mantener sus privilegios, dictadurasmilitares yestados de seguridad nacional (entiéndase, de seguridad del capilal).

Contenido ético-religioso. La liberación denuncia la ausencia de libertad y la urgencia de conquistarla. Sectores significativos de las iglesias cristianas latinoamericanas, en su gran mayoría religiosos, se incorporaron, ya en los años 60 , al movimiento de los oprimidos, y elaboraron una práctica religiosa y una comprensión teológica que legitimaba los intereses liberadores de los empobrecidos a la luz de la propia tradición biblica, de la práctica y del evangelio de Jesús. De la confrontación entre fe e injusticia social, y como reflexión a partir de prácticas políticas de los cristianos, nació la teología de la liberación.

Contenido pedagógico. La categoría de liberación establece una nueva relación entre el agente social y el pueblo, entre el poder polílico y la sociedad civil, entre el profesor y el alumno. Liberación implica partir de las capacidades del otro, negarse a imponerle recetas y crear condiciones para que ejerza su libertad y creatividad. El brasilento Paulo Freire elaboró toda una Pedogogía del oprimido y cómo entender la Educación como práctica de libersad.

Conienido utópico de la liberación. Liberación supone un proceso abicrto de superación de todas las servidumbres: traduce también un anhelo secular de los seres humanos, el de hacemos hombres y mujeres nuevos, creadores de un mundo nuevo. En este sentido, liberación significa la emergencia epocal de una nueva conciencia histórica ${ }^{27}$ Todo puede ser leído desde la óptica de liberación-opresión. ¿En qué medida ayudan las diversas prácticas y los diversos saberes a la liberación de los pueblos y de las personas? Cada ciencia deberá desarrollar su dimensión liberadora: la filosofía, la teología, la educación, la medicina, la sociología, la historia, las ciencias naturales. La liberación se ha trasnformado en la bandera de todos los que han tomado conciencia de opresiones específicas, las mujeres, los negros, los indígenas, las prostitulas. Cuando emerge este nuevo estado de conciencia, todos quedan enfrentados con esta pregunta crucial: ¿De qué lado se encuentra usted? ¿Qué intereses subyacen a su práclica, su saber, su siluación social? ¿Favorecen al status quo? ¿Buscan solo mejorarlo? ¿Nos mantienen abiertos a nuevos avances de la libertad? ¿Implican una altemativa que permita una mejor forma de integración de todos y la superación de determinados niveles de contradicciones 
y conlictos? Aquí se capta si en verdad oplamos por la liberación, por el reformismo, el conservadurismo, o incluso por el rcaccionarismo.

Desde la óptica de la liberación podemos relcer la historia latinoamericana e identificar las vertientes liberadoras. Es leer la historia desde los vencidos, pero no resignados, alimentando siempre los anhclos de liberación. Veamos algunos pasos desde el reverso de esta hisloria.

\section{a) El sentido liberador de la defensa del indio}

En el siglo XVI encontramos una pléyade de obispos que defienden al indio, pero no tanto como asunto cultural, por ser indio, sino como asunto social, por ser explotado. ${ }^{28}$ Bien decía Bartolomé de las Casas: "Vale más un indio infiel, pero vivo, de lo que vale un indio cristiano, pero muerto."29 Junto con Bartolomé, obispo de Chiapas (1544-1547), encontramos a Antonio Valdivieso, obispo de Nicaragua (1544-1550); Juan del Valle, obispo de Popayán (1548-1560); Diego Medellín, obispo de Santiago de Chile (1576-1592) o al P. Antonio Vieira, en Brasil, y a tantos otros misioncros domínicos, franciscanos y mercedarios. Para mejor defender a los indios, los misioneros Iranciscanos y jesuílas pensaron en un sisterna alternativo al colonial, las reducciones del siglo XVII y XVIII en territorios que hoy son Paraguay, Brasil, Perú, México e incluso California. En estas reducciones, el indígena, aunque bajo la orientación de los misioneros, se convertía en sujeto de su propia organización económico-social.

\section{b) El sentido liberador de las insurrecciones indígenas}

La dominación ibérica fue violenta para con los indigenas, ${ }^{30}$ pero muchos resistieron hasta la muerte, como los tomoios en Río de Janeiro. Los caribes de las Antillas, los araucanos de Chile, los charrúas de Uruguay y los calchaquís de Argentina, fueron quienes ofrecieron mayor resistencia, pues se alzaban conlinuamente contra la colonización. Juan Santos Atahualpa coordinó insurrecciones indígenas en Bolivia entre 1735 y 1750 . En estas insurrecciones participaron también negros y mulatos, lo cual confirma que se trataba realmente de una resisıcncia a la explotación colonial española y de búsqueda de la libertad. La guerra de los cabanos en el nordeste brasileño es un ejemplo típico de esta combinación de explotación: entre 1832 y 1850 los indígenas, esclavos negros y campesinos pobres promovieron una verdadera gucra de liberación contra el gobierno colonial de Pemarbuco. ${ }^{31}$ Entre 1780 y 1783 el cacique Túpac-Aman organizó una fenomenal insurección de indígenas de Peni, Bolivia, Ecuador y del none de Chile y Argentina. La víspera de su ejecución, Túpac-Amaru se enfrentó con el virrey y entonces dijo la famosa frase que descifra el sentido de todas las rebeliones liberadoras de los indigenas: "Los únicos conspiradores somos vos y yo. Vos, como opresor del pueblo; y yo, por haber intenlado liberarlo de esta tirania." 32

\section{c) El sentido liberador de los quilombos negros}

Ya se ha escrito que lo esencial del capitalismo mercantil consistió en la escla- 
vitud. ${ }^{33}$ Efectivamente, el tráfico en el Alántico habría traído de Africa a América cerca de 9.5 millones de esclavos, de los cuales 4.7 millones vinieron a América Latina. ${ }^{34}$ La historia de la población negra latinoamericana es la historia de los supervivientes. La dominación fue tan feroz que durante el período portugués los esclavos negros tenían una expectativa de vida de no más de 5 a 7 affos. ${ }^{35}$ El número de fugitivos y la organización de "cimarnones" y "quilombos" (organizaciones de esclavos fugitivos) se cuentan por centenares. ${ }^{36}$ La más famosa en Brasil fue la república de los Palmares, entre Pemanbuco y Bahía (en el nordeste brasilefio), entre 1630 y $1695 .{ }^{37}$ En esta república se daba una práctica, comunitaria y socialista, en el uso de las tierras y en la producción, una libertad política que no existía para nadie en la colonia. Hay que recalcar también la revolución de los alfaiates, en Bahía en 1789, llevada a cabo por negros y mulatos quienes proclamaron la "república de Bahía," como se decía en la constitución "con un gobiemo republicano libre e independiente, en que todos tenían la posibilidad de acceder a los puestos y ministerios públicos sin distinción entre criollos y negros. ${ }^{n 38}$

Además de estas rebeliones, conocemos las de los criollos que querían independizarse de la colonia y constituirse como sociedad autónoma. Las más importantes son las de Asunción de Paraguay (1721 y 1730) y la rebelión de los "comuneros" de Socorro en Nueva Granada, Colombia, en 1781, movimiento que se extendió también por Venezuela y Ecuador. ${ }^{39}$ Estas revoluciones de indígenas, negros, mulatos y criollos, no estaban inspiradas en las ideas de la Aufklärung (ilus(ración), sino que nacieron como respuesta desesperada contra la opresión, y buscaron caminos de liberación. Fueron derrotadas, pero su memoria está hoy siendo rehecha - con gran dificultad pues los oprimidos no dejan documentos ni monumentos- por quienes en la actualidad, en la sociedad latinoamericana, se comprometen con una alternativa al capitalismo. Existen movimientos populares, importantes sectores del sindicalismo, de las iglesias cristianas, partidos políticos de corte popular y liberador que encarnan la voluniad de liberación gestada durante tantos siglos de opresión. Para todos ellos, la palabra liberación no es una moda, sino una esperanza de vida que sólo podrá llegar a ser realidad a través de un costoso proceso de liberación.

\section{Tradiciones europeas de libertad}

Después de haber reflexionado brevernente sobre la situación de opresión histórica y los intentos de resistencia y liberación latinoamericanos queremos hacer memoria, en el brevísimo tiempo que nos queda, de algunas tradiciones europeas de libertad. Nos contentamos con hacer algunas indicaciones, pues presuponemos que la temática es ya del conocimiento general. Pero antes que nada es importante hacer notar las diferencias entre América Latina y Europa. Eso explicará, en buena medida, por qué en Europa se habla preferentemente de libertad y en América Latina de liberación.

Europa es "metrópoli" y América Latina es "colonia" Por ello, Europa es independiente y Amnérica Latina es dependiente. Europa tiene un proceso económico 
y político autogestionado, América Latina un proceso subordinado, asociado a otros y controlado desde fuera. Europa es blanca, América Latina es indígena, negra, mestiza, blanca con diversos matices culturales, por lo tanto, y con modos de producción complejos. La especificidad europea reside en su autodeterminación y en su autonomía; por ello habla de libertad como algo ya dado, por lo menos para las clases dominantes y los asociados a ellas. La especificidad latinoamericana está en la dominación y la alienación de todos, incluso de las clases dominantes nacionales que dependen de los centros de poder en las metrópolis. La libertad no es algo dado, sino algo que es negado y debe ser conquistado. Por ello se habla de liberación como la acción creadora que debe recuperar la liberlad cautiva o crear la libertad.

\subsection{Límites y contradicciones de las libertades europeas}

Veamos algunos momentos de la historia de la libertad europea. En general podemos decir que la historia de Europa está hecha de revoluciones, ${ }^{40}$ la revolución antropocéntrica, historiocéntrica, científico-tócnica, religiosa, política, socialista, etc. Y toda revolución, tal como nos lo insinúa Hanna Arendt, es un acto que funda la libertad (constitutio libertatis). ${ }^{41}$ La libertad está en el centro de las prácticas y del pensamiento europeo a partir del siglo XVI.

En primer lugar, en el siglo XVI se dio el viraje antropológico, gracias a condiciones económicas y políticas adecuadas. El cosmos no es ya el centro, sino que lo es el ser humano como subjetividad (ego). Esta subjetividad se muestra como autonomía, como libcrad, como posesión de sí mismo y como posesión del mundo, en una palabra, como voluntad de poder. Esta libertad se objeliva en la historia y Hegel entenderá la filosolía como ciencia de la libertad. ${ }^{42}$ En sus Lecciones sobre la filosofía de la historia define la historia como "el progreso en la conciencia de libertad."43 Esta subjetividad implantará un nuevo tipo de saber, la racionalidad instrumental. ${ }^{44}$ Saber es poder, el poder es dominio sobre cualquier objeto, la naturaleza, el hombre y la sociedad. El ego cogito filosófico de Descartes se traduce por el ego conquero político de Hemán Cortés.

El descubrimiento de la subjetividad repercutió también en el cristianismo. La reforma de Lutero representa la afirmación de la liberıas christiana del individuo frente a la dominación clerical. La alirmación del sacerdocio común de los fieles puso en jaque al poder del cuerpo jerárquico y al poder político ligado a aquél. La reforma no estaba dirigida simplemente contra los abusos del clero o la comupción de las doctrinas, sino también contra las injusticias sociales. ${ }^{45}$ En la Biblia no se buscaba sólo la doctrina de la justificación, sino también argumentos para defender la igualdad fundamental de lodas las personas. No sin razón la llama Hegel la Haupirevolution. ${ }^{46}$

La revolución antropocéntrica está en la base de la revolución científico-técnica. ${ }^{47} \mathrm{El}$ saber operativo libera de aquellos amuletos, enemigos de la humanidad, como son la ignorancia de las causas de los fenómenos de la naturaleza y de las enfermedades humanas. El proyecto cientílico-lécnico se impuso, a partir de Euro- 
pa, a toda la humanidad; y constituye hoy la forma dominante de acceder a la realidad. Este proyecto tiene como su portador histórico a la clase burguesa, y ella llevó a cabo una de las mayores revoluciones históricas de la humanidad: la revolución francesa. Lo que en ella estaba en juego era la conquista de las libertades políticas de los ciudadanos conura el arbitrio de los reyes o de los estados absolutistas. Todas las libertades modernas encuentran un punto de referencia obligado, incluso cuando esto se hace para mostrar su insuficiencia, en la revolución Irancesa y en la declaración de los derechos del hombre. Los ideales de esta revolución incendiaron los sectores más progresistas de América Latina, intelectuales, políticos y clérigos; y de este ambiente surgieron los próceres que consiguieron la independencia política de las diversas naciones latinoamericanas. $4 \mathrm{~B}$

Lo especílico de la revolución francesa se encuentra en la exigencia radical de libertad a partir del hombre universal. La Insirucción de Lyon, del 16 de noviembre de 1793, que profundiza los ideales revolucionarios, expresa también la conciencia social de la revolución: "Mientras sobre esta tierra existan miserables, no se ha construido todavía el camino de la libertad... La revolución sería un contrasentido político y moral si pusiese su objetivo en asegurar el bienestar de algunos centenares de personas y eternizar, al mismo tiempo, la miseria de millones." ${ }^{49}$ En el decurso de la historia, cuando la burguesía dejó de ser una clase revolucionaria y se convirió en clase dominante, hizo prevalecer sus intereses y cré́ un tipo de sociedad marcada por el Ethos que ella misma proyectó, individualista, eficientista y acumulador, a costa de la explotación de los trabajadores.

A los trabajadores no les benefició el movimiento liberal; se convirtieron en combustible para el ingente proceso de industralización que emprendió la burguesía liberada. Los movimientos obreros, que comenzaron en Inglaterra, entendieron que su libertad iba unida a la trasnformación de las estructuras económicas del capitalismo burgués. A la propiedad privada de los medios de producción opusieron la propiedad social de estos medios. No fue el marxismo el que originó este movimicnto, más bien lo supone y vive en función de él. La revolución obrera proletaria triunfó en Rusia en 1917. Esta revolución es la revolución de nuestros tiempo, ${ }^{50}$ pues permitió la irrupción de un nuevo sujeto histórico, el prolctariado, portador de un nuevo principio ordenador de la sociedad, el socialismo, capaz de ampliar todavia más las libertades conquistadas por la burguesía.

Todas las revoluciones significaron avances innegables en el camino de la libertad. Para quienes se sentían oprimidos y privados de libertad, estas revoluciones se han constituido en verdaderos procesos de liberación. Pero desde la perspectiva latinoamericana, desde la periferia, estas conquistas ofrecen también limitaciones que quisiéramos presentar ahora.

La subjetividad moderna, en cuanto libertad, no supo, al confrontarse con el otro, el indígena, reconocerlo como otro. El otro fue considerado como animal, bárbaro, rudo, "de la misma estirpe de aquella de la santa arca de Noé" (animales); $;^{51}$ es decir, al otro se le negó la subjelividad y la libertad. Por ello los indígenas fueron atropellados e incorporados simplemente a la mismidad europea. 
La libertas christiana de la relorma encontró su principal limilación en lo relerente a la reforma popular. Los príncipes, no sin la complicidad de Lutero, intervinieron y sofocaron totalmente la significación liberadora de los campesinos que se rebelaron. Los principales beneficiarios de la reforma, así como de la Contra-reforma, fueron los reyes, los príncipes y los nobles.

Las libertades de la revolución francesa eran justas, pero sus revolucionarios, como St. Just y M. Robespierre, no cayeron en la cuenta de las condiciones cconómicas necesarias para su efectiva universalización. Al mismo tiempo que se proclaman los derechos del hombre, el proyecto colonizador europeo sometía duramente a hombres y mujeres en América y en Africa desde las potencias colonizadoras europeas.

La revolución socialista hizo, en efecto, la revolución del hambre, es decir garantizó los derechos sociales fundamentales para la población, pero pagó el alto precio de la libertad política y de expresión; siendo así que es importante incorporar también a aquella revolución la revolución de la libertad que tanta sangre había costado. Este sigue siendo el desafío permanente para el proyecto socialista.

\subsection{La memoria europea de los revolucionarios vencidos}

Hasta aqui nos hemos referido a las revoluciones triunfantes y a las libertades que éstas han traido consigo. Pero hay que mencionar también a los movimientos revolucionarios, realmente liberadores, que cayeron vencidos, pero cuya memoria, recuperada, sirve de aliento a los modemos movimientos de liberación. No vamos a referimos a movimientos anteriores a la época modema (los movimientos pauperistas medievales, los diversos milenarismos, el movimiento husita en Bohemia y otros) sino que nos ceñimos a los de la época modema, que corresponden a la época de la invasión de América Latina.

En este contexto hay que mencionar indiscutiblemente a Thornas Müntzer, el primer teólogo de la revolución (1525). ${ }^{52}$ Müntzer se insertó en la revolución de los campesinos (1525) y procuró traducir las intuiciones de Lutero al nivel popular. A éste le critica duramente, sobre todo, su doctrina de la fe sin obras: no tener en cuenta las obras es entregar al pueblo a la dominación de los príncipes, es permitir que vuelva a instalarse el clericalismo, es, finalmente, renunciar en la práctica a la comunidad apostólica, el ideal de convivencia para la relorma. Según J. Comblin, la verdadera revolución protestante, con todo, fue la revolución puritana de Inglaterra entre 1640 y 1660.53 Ahí están germinalmente las modernas liberlades, la libertad individual, los derechos del hombre, la democracia, la tolerancia religiosa. Cromwell, quien personificó la revolución (puritana) de los Santos, decía ante el parlamento en 1654: "Libertad de conciencia y libertad de los súbdios. Tales son las dos cosas por las que nos debernos batir firmemente." 54 Esa revolución fue absorbida por la restauración, pero sus ideas emigraron a Estados Unidos y ayudaron a hacer la revolución norteamericana. Hubo muchos otros movimientos ligados a la lucha obrera en Alemania, en Inglatera y en Italia con formulaciones liberadoras. Sólo queremos recordar a los socialistas utópi- 
cos, como Saint-Simon, Fouricr y Owen, quicnes presentaban, desde una perspectiva religiosa, una libcración de las opresiones del capitalismo industrial.55 Marx, en nombre del socialismo científico, los combatió duramente. Pero hoy vemos que estos dos modos de formular el socialismo no tienen por qué ser conurapuestos. La utopía pertenece también a la realidad y el socialismo historico no rcaliza todos los ideales del proyecto socialista. Siempre hay una dimensión utópica en toda práctica humana también polílica. Ese socialismo utópico es útil para mantener a la socicdad en proceso, superando sus propias conquistas, y para alimentar, en todos, los ideales que van en línea de una democracia fundamental, participativa y social. Entre esos europeos que fueron vencidos y los vencidos y oprimidos latinoamericanos existen vigorosos lazos de solidaridad en un mismo destino. La clasc obrera oprimida que consiguió afirmarse en el poder por la revolución socialista sigue siendo una llamada a la práctica liberadora de nuestros empobrecidos, pucs son los totalmente marginados en el sistema de producción capitalista, los sin ticrra, los indígenas recluídos en sus reservas, los millones de desempleados o subempleados. Todo este bloque histórico se halla, estructuralmente, en una rclación de connaturalidad con las luchas de los obreros europeos que triunfaron.

\section{Una opción por una liberación integral hecha por Europa y por América Latina}

Las reflexiones que hemos hecho hasta ahora muestran que América Latina y Europa están ligadas profundamente, aunque por relaciones muy desiguales. La Europa colonizadora consuituye uno de los factores principales, no el único, de que América Latina sea tal como es hoy: un continente dependiente, empobrecido y animado por una gran esperanza de liberación. Tanto la opresión como los ideales de liberación vinieron de Europa; el proceso de liberación, sin embargo, ha sido obra de nuestros oprimidos y está todavia en marcha Lo que causa dificultades en este proceso es, en gran parte, la pérdida de identidad latinoamericana causada por la violencia de la invasión ibérica. En verdad, los ibéricos no supieron ver en el indigena, en el negro, en el mestizo, al otro que debe ser respetado, la alteridad que debe ser acogida. Avasallaron al otro y lo subyugaron cuando no lo destruyeron totalmente. El proceso de liberación implica, cn primer lugar, la recuperación de la propia identidad, de la memoria solocada de las culturastestimonio (Darcy Ribeiro) y, después, la lucha por crear espacios para la necesaria libertad de expresión y de difusión.

¿Qué es lo que podemos hacer nosotros, latinoamericanos y europeos? Este es el gran desalio que nos presenta el nivel de conciencia que vamos adquiriendo conjuntamente. Debcmos estar juntos en este inmenso proceso de liberación que envuelve a los opresores históricos y a los oprimidos latinoamericanos. América Latina jamás será liberada sin que, a su vez, se libere Europa de sus aliados (del Allántico Norte y Japón). Todos nos encontramos dentro de un único y colosal proceso histórico y sistema de producción. Pero este proceso acaece de forma desi- 
gual, pues los benelicios del desarrollo son apropiados por los países ya desarollados, las antiguas potencias colonizadoras, y los maleficios del sistema o sus beneficios secundarios van a las naciones subdesarrolladas, las antiguas colonias en América Latina, Africa y Asia. Las relaciones entre ambos polos, el desarrollo y el subdesarrollo, no son de interdependencia, como acosturnbra decir la ideología oficial, sino de auténtica dependencia que significa opresión económica, política y cultural. La dcuda extema del tercer mundo, ingente e impagable, muestra esta dependencia opresora y la disimetría existente en las relaciones internacionales.

Ciertamente no existen soluciones inmediatas y fácilmente comprensivas para todos. Es importante, e incluso imprescindible, comprender que la rclación dependencia-opresión e independencia-liberación, que envuelve a Europa y a América Latina, es fundamental. Los europeos y nuestras clases dominantes latinoamericanas hemos sido cómplices de la dominación de nuestro pueblo. Ahora debemos ser sus aliados en el proceso de liberación. Es preciso que veamos con simpatía y sin prcjuicios el fenómeno fundamental que está ocurriendo en las sociedades latinoamericanas y también en las periferias de Europa: el pueblo latinoamericano ya ha despertado de la opresión histórica en que vive y a la cual fue sometido. Sectores importantes de intelectuales universitarios y de las Iglesias cristianas ya han asumido su causa como aliados. Ya existen prácticas alternativas que vienen de abajo, del pueblo organizado, que apuntan a una sociedad alternativa en la que prevalecerá la đemocracia social y iendrá en las organizaciones populares su principal sujeto histórico para llevarla a cabo. La teología de la liberación nació hacia mediados de los años sesenta como reflexión crítica sobre estas prácticas y al interior de estas prácticas, como teología elaborada por militantes cristianos, teólogos y obispos que tomaron en serio la opción por los pobres, en contra de su pobreza y a favor de su liberación. Hoy, cada vez más profesionales de todos los campos del saber están asumiendo este desaflo histórico: Lcómo contribuir desde mi propio trabajo, de mi saber y de mi compromiso a la liberación de los oprimidos? De esta forma muchos superan el cinismo de una ciencia que se mantiene disante del proceso social y se muestra indiferente frente a la miseria del oprimido.

Es alentador ver que en Europa cada vez más personas comprenden el drama político-social de América Latina y sus vinculaciones con la dominación europea. ${ }^{56}$ Estas postulan un proyecto de transformación global que supere las relaciones de dependencia y de opresión. Es éste un proyecto revolucionario de largo alcance. Tal vez, ni nuestra generación ni la próxima vea su concreción. Pero lo importante es si podemos ver el problema y si asumimos una posición ética, política y religiosa correcta. Quiero deslacar aquí los aportes que proporcionan las teologías de dos colegas y profesores: Johann Baptist Metz con su teología política y Jürgen Moltmann con su teología de la esperanza y de la comunión, las cuales denuncian la pérdida del significado político-social del evangelio y recuperan el aspecto revolucionario que está presente en la práctica y en la memoria peligrosa de Jesucristo. Esos teólogos ayudan a que las iglesias presten su colaboración en 
este ingente proceso, mesiánico diría yo, de liberación integral. $\mathrm{Y}$ ellos han sido escuchados por nuestras iglesias latinoamericanas, tal vez con mayor atención y con mayor voluntad de eficacia que en sus propias iglesias-madres, lo cual muestra cuán pertinentes y acertadas son sus teologías. Tampoco hay que olvidar los numerosos grupos que en la sociedad civil han asumido la causa del tercer mundo y que hacen de la temática de la liberación marco teórico de referencia para sus prácticas y motivaciones.

No tengo ninguna receta que ofrecer ni entreveo una liberación inmediata. Pero no por ello caemos en la resignación. Creo que los problemas que he presentado son objetivos y no equivocados. Por ello, me parece importante mencionar los siguientes puntos.

Es necesario profundizar en el conocimiento del problema libertad europea y liberación latinoamericana y las relaciones de dependencia entre uno y otro polo. Hay que superar meros paralelismos del conocimiento y saber articular, más bien, la comprensión latinoamericana y europea en un horizonte común y en un proceso histórico-social que nos comprometa a todos. De esta prolundización debe surgir una opción por la liberación como respuesta adecuada a los desafíos de la opresión generada por el sistema mundial del capilal. Al menos al nivel teórico, quizá hayamos dado ya el viraje copernicano, de un pensamiento que acaba reproduciendo y reforzando el sistema hacia otro en la línea de un pensamiento que le es negativo, crítico y revolucionario.

Es necesario, además, incrementar la solidaridad entre Europa y América Latina en términos de experiencias y confrontación de perspectivas para que lleguen a ser complementarias y todas ellas refuercen el proceso de liberación de los oprimidos de allá y de acá

Allá donde estemos, pensando, trabajando y actuando, en la sociedad y en nuestros campos específicos de trabajo, hay que pensar y actuar de forma liberadora, de forma altemativa al sistema imperante con sus utopías engañosas y sus ídolos deshumanizantes. No podemos simplemente esperar a que llegue la gran aurora de la liberación. No vendrá sin prácticas humanas ni sin muchos sacrificios. "Más vale la lágrima de la derrota que la vergulenza de no haber participado."

Desde ahora debemos ensayar aquello que se opone a todas las formas de dominación y opresión: la democracia. El capitalismo es incompatible con los ideales democráticos, pues el capitalismo entroniza la acumulación por un lado y la pobreza por el otro, transforma las diferencias en desigualdades, y no permite la igualdad de participación en el trabajo mientras que sí se la concede al capital. No me estoy refiriendo aquí, por tanto, a la democracia burguesa, sino a la democracia tout court. Más que una formación social, la democracia supone una aclitud que debe ser vivida en lodas las esferas de la vida, de la intersubjelividad y de la sociedad. Los ideales democráticos son profundamente revolucionarios; subvierten todas las formas de dominación de unos sobre otros. La democracia constituye también uno de los más antiguos sueffos de occidente. Posee una dimensión utó- 
pica, en el sentido de que ilumina cada momento de la vida y de que nunca puede agotarse en ninguna concreción histórica. Su inspiración continúa produciendo nuevas formas de convivencia.

Desde la experiencia con grupos de base de América Latina en donde se intenta, ya ahora, vivir el espíritu democrático y la alternativa de la libertad, vemos la democracia asentada sobre estos cuatro pilares, como sobre las cuatro patas de una mesa. ${ }^{57}$

La mayor participación posible de todos en todas las cosas que conciemen a todos. Esa participación debe comenzar desde abajo para que nadie quede marginado. Todos tienen algo que contribuir, pues cada uno posee su inteligencia.

La igualdad de todos como resultado de formas lo más englobantes posible de participación. Cada uno es diferente de otro, pero la participación impide que la diferencia se convierta en desigualdad. Lo que permite que surja la justicia social son las relaciones basadas en la igualdad de derechos y de dignidad.

La diversidad respelada y acogida, no como amenaza a la igualdad, sino como expresión de la riqueza de formas de paricipación y đe igualdad. No sólo una fuga de Bach expresa la belleza musical, sino la diversidad de géneros musicales, la sinfonía, la ópera, el gregoriano, la canción o la samba. Así es cambién en la vida social: la diversidad de expresiones muestra las virtualidades de la igualdad.

La comunión como capacidad del espíritu humano de relacionarse fratemalmente unos con otros y de entrar en comunión con Dios. Existe en el ser humano una profundidad sagrada que encuentra su mejor expresión en la fuerza de comunión desinteresada con los más débiles y con el Transcendente.

Estas cuatro dimensiones viven juntas. El intento de concretizarlas nos permite superar, allá donde estemos, los mecanismos de la opresión. Latinoamericanos y europeos nos vemos desafiados a reforzar la democracia de corte social, popular, participativo y transcultural. La democracia es la portadora concreta de la liberación de aquellos que históricamente han estado situados en polos opuestos, unos en el polo de los dominadores y otros en el de los dominados. La democracia opera la revolución de ambos, permiliendo que consıruyan juntos, ya ahora, formas de convivencia sin dominación. De esta nueva síntesis ya hay expcriencias germinales. Hay mucho que andar todavía, y juntos debemos conseguir que llegue a sazonar del día que permita ese tipo de democracia.

Por ello, y con esto termino, cs preciso que tengamos la esperanza humana y política en la capacidad de desmoniar los mecanismos hisıóricos de dominación. Estos mecanismos no provienen de la naturaleza; surgieron un día de prácticas distorsionadas de seres humanos y de mecanismos socio-económicos. La liberación es posible y es el ejercicio más noble y elevado de la liberlad humana. Hago mias las palabras de un líder sindical y político brasileño que expresan bien esla esperanza: "Los opresores pueden pisotear el jardín de los oprimidos; pueden quebrar una, dos, diez rosas y hasta todas ellas. Pero no podran impedir la venida de la primavera de la liberación de los oprimidos." 
Notas

1. Cfr. D. Ribeiro, As Américas e a Civilizaçđo, Perrópolis, 1986; Id., O dilema da America Latina. Estructuras de pader e forças insurgentes, Petropolis, 1987.

2. Cfr. E. Dussel, Historia de la Jglesia en América Latina. Coloniaje y liberación, Barcelona, 1974; Id., "América Latina e consciência crista." en Caminhos de libertaçao latino-americana II, Sāo Paulo, 1985, 7-40; G. Gutiérez, Teología desde el reverso de la historia, Lirna 1977; S.S. Gotay, O pensamenso cristso revoluciontrio na América Latina e no Caribe, S. Paulo, 1985; E. Galeano, As veias abertas da America Lasina, Rio de Janeiro, 1978; R. Zimmemann, América Latina $\longrightarrow$ na-ser, Petrópolis, 1987.

3. Cfr. Ribeiro, As Américas e a Civilizaçdo. Processo de formaçâo e causas do desenvolvimento desigual dos povos americanos, Petrópolis, 1976; Id., La cultura, Latinoamericana, México, 1978.

4. Cfr. P. Chaumu, La populasion de I Amérique indienne, en Revue Historique, Juilsept. (1964) 111-116; S. Cook y W. Borah, The Indian population of Central Merico 1535-1610, Berkeley, 1960.

5. Cfr. B. Ribeiro, $O$ indio na história do Brasil, S. Paulo, 1984, 29.

6. "Brevísima relación de la destruceión de las Lndias," en Obras escogidas V, Madrid, 1961. El texto se encuentra en "Mernorial al consejo de Indias" (1565) publicado y comentado por J. B. Lassegue, La larga marcha de las Casas, Lima, 1974, 387.

7. Cfr. G. Bonfil, "La historia desde abajo." en Hacia el nuevo milenio II. Mérico, 1986, 82.

8. Cfr. Mires, La colonización de las almas. Misión y conquista en Hisponanérica, San José de Costa Rice, 1987.

9. Cfr. Revista Eclesiástica Brasileira, 47 (1987) 182-183; Aporte de los pueblas indigenas de América Latina a la teología cristiana (II consulta ecuménica de pastoral indfgena), 1986

10. E. Dussel, História da teología latina-americana, STo Paulo, 1981, 166.

11. Lumpenburguesía: Lumpendesarrollo, Mérico, 1971, 23.

12. P. Richard, Morte das cristandades e nascinenso da Igreja, Sło Paulo, 198233.

13. D. Ribeiro, La cultura latinamericana, op. cir., 28.

14. Una muy buena presentación en E. Dussel, "Bartolomeu de las Casas no quinto centenário de seu nascimento," en Caminhas de libertaçón latino-anericana II. S. Paulo, 1985, 135-150.

15. "BrevIsime relncion," op. eir., 36.

16. Id., Ibid.

17. Cfr. J. M. Paiva, Colonização e catequese, S. Paulo, 1982, 41-46; J. H8ffiner, Kola nialismus und Evangelium, Trier, 1969, $189 \mathrm{s.}$

18. E. Dussel, El episcopado latinoamaricano y la liberación de las pobres 1504-1620. México, 1979.

19. Cfr. P. Richard, Morte das cristandades, op. cis., 31-46.

20. Cfr. O. Ianni, Imperialismo y culsura de la violencia en América Latina, Mérico, 1974.

21. O. Ianni, La formación del Estado populista en América Latina, México, 1975.

22. Cfr. G. Arroyo, "Pensamiento latinoamericano sobre subdesarrollo y dependencia extema," en Fe cristiana y cambio social en América Latina, Salamance, 1973, 305321. 
23. Cfr. H. Assmann, Opresión-liberación: desafio a los cristianos, Montevideo, 1971.

24. G. Gutiérrez, La fuerza histórica de los pobres, Salamanca, 1982 96-130.

25. Cfr. G. Cerqueira Filho, $A$ influencia das ideias socialisias no pensamento polltico brosileiro (1890-1922), S. Paulo, 1982; C. G. Mota, Idéa de revoluçāo no Brasil (1789-/801), Petróplis, 1979.

26. C. Boff, et alii, "Ferramenta Marxista" (Comunicaçōes ISER, 25), Rio de Janeiro. 1987.

27. L. Boff, Teologia do cativeiro e da libertaçso, Petrópolis, 1985, 13-26; H. J. Prien, Lateinamerika: Gesellschaft, Kirche, Theologie, 2 Bd., Gottingen, 1981.

28. Cfr. P. Richard, Morte das cristandades, op. cir., 35.

29. "Entre los remedios" (1545), en Obras escogidas V, Madrid, 1958,118; G. Gutiérrez, La fuerza histórica de los pobres, op. cil., 250.

30. V. Alba, Le mouvement ouvrier en Amérique Lasine, Paris, 1933, 47-58; P. Richard, Morte das cristandades, op. cil., 43-44.

31. Cfr. D. Lindoso, A usopia armada. Rebelioes de pobres nas masas do Tombo Real (1832-1850), Río de Janciro, 1983.

32. Cfr. B. Lewin La rebelión de Túpac-Amaru y las orígenes de la independencia en Hispanoanérica, Buenos Aires, 1967; J. Kraiber, "Religión y justicia en TúpacAmaru," en Raíces de la teología latinoamericana, San José, 1985, 75-84.

33. Cfr. E. Williarns, Capitalism and Slavery, Londres, 1975.

34. Cfr. J. O. Beozzo, "As Américas negras e a história da Igreja: questóes metodológicas," en Escravalura negra e história da lgreja na América Latina e no Caribe, Perrópolis, 1987, 27-64, aquí 34-35; Ph. Curtir, The Allansic Slove Trade, Wisconsin University Press, 1969.

35. Cfr. M. Bergmanr, Nasce um povo, Peró́polis, 1977, 50.

36. Cfr. L. Luma, O negro na luta contra a escravidāo, Brasilia 1976; A.M. Pescatello, The african in Lafin America, Nueva York, 1975; J. Fouchard, The Haitian Marrons: liberty or death, Nueva York, 1981; Cl. Moura, Quilombos: resistência ao escravismo, S. Paulo, 1987.

37. Cfr. D. Freitas, Palmares: a guerra dos escravos, Porlo Alegre, 1984.

38. P. Richard, Morte das cristandades, op. cit., 45.

39. Id., Ibid.

40. Véanse algumos títulos: F: Heer, Europa, Muser der Revolusionen, Suttgart, 1964; H. E. Bahr, (Ed), Welffrieden und Revolurion, Hamburgo, 1968; E. RosenstockHuessy, Die europäischen Revolutionen und der Charalder der Nationen, Stutgart, 1951; H. Arendh, Uber die Revolurion, Müchen, 1963; H. Maier, Revolution und Kirche, München, 1973; E. Feil-R. Weth, Diskussion zw "Theologie der Reva Jution," Munchen-Mainz 1969; J. Comblin. Théologie de la révolurion, París, 1970.

41. Über die Revolution, op cit., 183-231.

42. Cfr. Ensyklopaedie der philosophisehen Wissenschafien 1830, Hamburgo, 1959, § 384A.

43. Vorlesungen über die Philosophie der Weligeschichte, Bd. I; Die Vernunft in der Geschichte (J. Hoffmeister, Hamburgo 1955), 63.

44. M. Horkheimer, Zwr Krisik der instrumentellen Vernunfi, Frankfurt, 1974; J. Habermas, Erkenunis und Inseresse, Frankfurh 1969.

45. Cfr. L. Boff, "A significação de Lutero para la libertaçāo dos oprimudos," en $E$ a Igreja se fez povo, Peró́polis, 1986, 183-200.

46. Cfr. J. Comblin, Théologie de la révolusion, op. cit., 126-132. 
47. Cfr. E. Hobsbawm, Industry and empire, Baltimore, 1969; Id., Europäische Revolutionen, Zurich, 1962.

48. Cfr. R. Soler, Clase y nación en Hispanoamérica, San José, 1977.

49. Citado de S. G. Papcke, "Weltrevolution als Friede," en Weltfrieden und Revolution, op. cit., 19.

50. J. Comblin, Théologie de la révolution, op. cit., 139

51. Cfr. E. Dussel, "A cristandade modema frente ao outro, do índio 'rude' ao 'bom selvagem"' en Caminhos de libertação latino-americana II, op. cit., 151-160, esp. 151.

52. Cfr. M.M. Smirin, Die Volksreformation des Thomas Müntzer und der grosse Bauernkrieg, Berlín, 1956.

53. Cfr. M. Walzer, The Revolution of the Saints. A Study in the Origins of Radical Politics, Londres, 1966.

54. H. Kohn, The Idea of Nationalism, Nueva York, 1958.

55. Cfr. P. Pombeni, Socialismo e cristianesimo (1815-1975), Brescia, 1977.

56. Cfr. G. Hasenhüttl, Freiheit in Fesseln. Die Chance der Befreiungs-theologie, OltenFriburgo, 1985; K. Rahner, (Org.), Befreiende Theologie, Mainz, 1977.

57. H. de Souza, Construir a Utopia, Petrópolis, 1987, que nos ha inspirado en estas reflexiones políticas. 